\title{
Need and Solution to Transform the Manufacturing Industry in the Age of Industry 4.0 - A Capability Ma- turity Index Approach
}

\author{
Volker Stich ${ }^{1}$, Gerhard Gudergan $^{1}$, Violett Zeller ${ }^{2}$ \\ ${ }^{1}$ Institute for Industrial Management (FIR) at RWTH Aachen University, Campus-Boulevard \\ 55, 52074 Aachen, Germany \\ 2 i4.0MC - Industrie 4.0 Maturity Center, Campus-Boulevard 55, 52074 Aachen, Germany \\ gerhard.guderganefir.rwth-aachen.de
}

\begin{abstract}
Digitalization is changing the industrial landscape in a way we did not anticipate. The manufacturing industries worldwide are working to develop strategies and concepts for what is labelled with different terms such as the Industrial Internet of Things in the USA or Industrie 4.0 in Germany. Many industrialized economies are driven by the production sector and this sector needs specific approaches and instruments to take up other than those approaches we know from start-ups and ventures coming from Silicon Valley and other places. In this paper, we demonstrate an appropriate approach to transform producing companies in a systematic and evolutionary approach.

In particular, the objective of this paper is to provide results from two initiatives which conceptually build upon each other and are of particular relevance for the production industry. First, we present a global survey on the state of implementation and the future perspectives of the concept Industrie 4.0 from 2016. Findings from this study have forced parts of the German industry to heavily invest into a common approach to accelerate change towards Industry 4.0 in order to stay competitive in worldwide economy. This approach is presented in a second part.
\end{abstract}

Keywords: Digital transformation, Industrie 4.0, maturity model, manufacturing industry

\section{Introduction}

Concept and vision of Industrie 4.0 is often defined as "real-time, high data volume, multilateral communication and interconnectedness between cyber-physical systems and people", in order to realize self-optimizing business processes [3]. This depiction of Industrie 4.0 concentrates primarily on a technological understanding with the objective that manufacturing companies achieve a competitive advantage. However, the fundamental economic lever of Industrie 4.0 lies in stimulating business processes through necessary decisions and real-time adaptations [2]. 
Combined with adequate organizational conditions, companies are able to react faster to growing market dynamics, to develop new products more quickly and precisely $[4 ; 9]$.

Many results presented in this paper were gained within the context of a conceptual reference framework developed by german Government for Industry 4.0. The initial study is from 2016 and polled 433 industrial manufacturing executives in five regions - China, France, German speaking countries, the United Kingdom and the United States. We applied a specific capability maturity model for our analyses. The results provide an understanding of industry preparedness for Industrie 4.0. The huge potential of Industrie 4.0 is clearly pointed out but there are significant differences between countries. These differences in turn initiated a significant investment of resources by a consortium driven by the German industry and the German academy of science and engineering ACATECH. The later revealed a reference model and open standard and was successfully applied to transform manufacturing companies towards Industry 4.0 [3].

\section{Background and Motivation: Global Benchmark of Industry 4.0 Maturity}

In 2015 and 2016, a comprehensive global research study assessed industry attitudes towards Industrie 4.0 in the aerospace, automotive, electronics, machinery and process industries in China, France, German speaking countries, the United Kingdom, and the United States. There was a focus defined on asset efficiency because this is considered an important performance indicator for the success of all kind of manufacturing innovation programmes including Industrie 4.0 programs. The study polled 433 executives through an online survey as well as telephone interviews. FIR at RWTH Aachen and the independent research firm Vanson Bourne conducted the study for the leading information systems provider Infosys $[4,5]$.

For the purpose of analysis, enterprises were categorized as "Early Adopters" or "Followers". The actual status from 2015 and the aspiration for 2020 was analysed by asset efficiency levers, industry and production type, and country. Respondents were asked to outline their current maturity levels on these levers and their target for 2020 on a four point scale. The research used the Industrie 4.0 framework, conceptualized by the German government and developed by industry leaders.

In 2015, the vast majority ( 85 percent) of companies were aware of the high potential in implementing Industrie 4.0, Only 15 percent of enterprises surveyed had already implemented dedicated strategies for asset efficiency. An additional 39 percent had partially implemented these strategies.

Nearly half of the respondents surveyed (48 percent) wanted to implement Industrie 4.0 solutions systematically by 2020 (see Fig. 1.1). Conversely, by 2020 still one fifth of the respondents indicated that they will have made at best piecemeal progress. 
Need and Solution to Transform the Manufacturing Industry in the Age of Industry 4.0 33

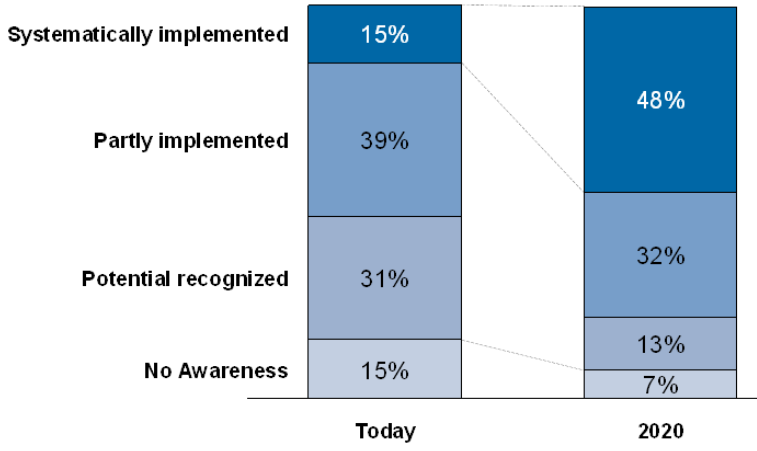

Fig. 1. 1 Use of Industrie 4.0 concepts to manage assets

The survey further found significant variance in the adoption levels in different markets. Figure 1.2 (see Fig. 1.2) below, shows that in 201568 percent of respondents from China had partially or systematically implemented Industrie 4.0 in asset management programs, estimated to increase to 89 percent by 2020. Comparable numbers for France are 27 percent and 58 percent respectively.

Across the five countries surveyed - China, France, Germany, the United Kingdom and the United States - the level of maturity in Industrie 4.0 varied significantly. While no country could claim to be the global early adopter in implementing Industrie 4.0, the percentage of companies in China that claimed to be early adopters was significantly higher than anywhere else (see Fig. 1.4).

2015

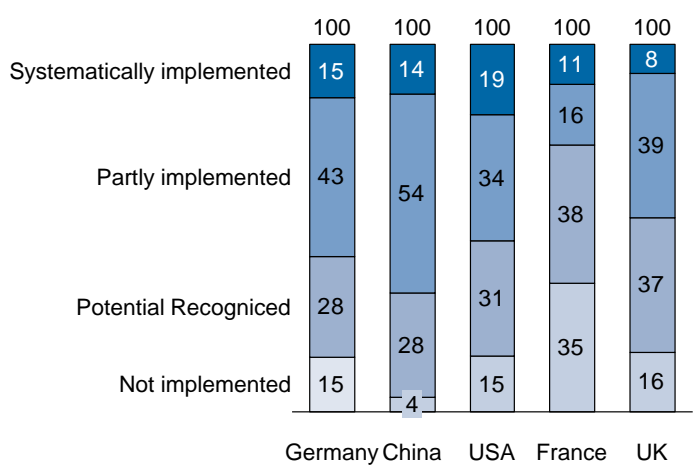

Fig. 1. 2 Country comparison of Industrie 4.0 concepts to manage assets in 2015 


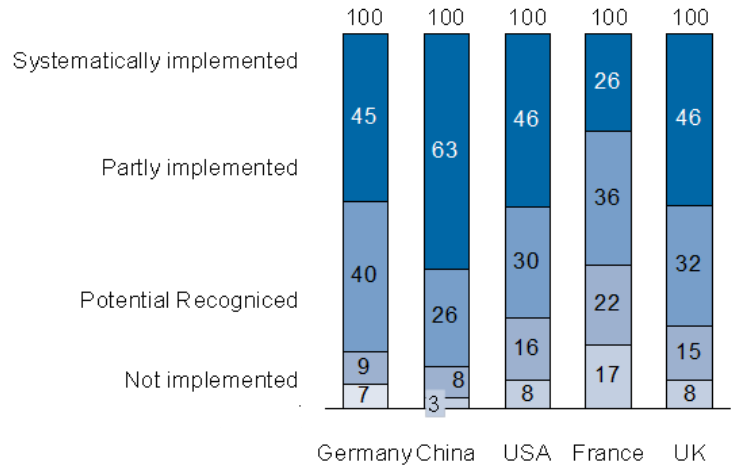

Fig. 1. 3 Country Country comparison of Industrie 4.0 concepts to manage assets in 2020

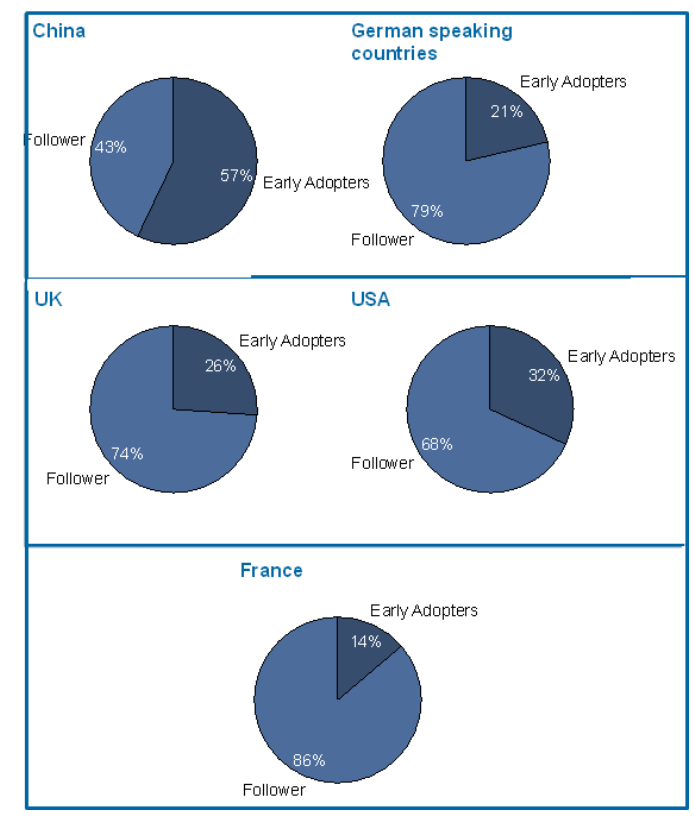

Fig. 1. 4 Early Adopter and Follower analysis by country

It is expected that a number of factors were and still are driving this; notably the focused initiatives and investment from the Chinese Government to develop more sustainable industry growth. Also manufacturing is core for China and the market is accustomed to rapidly implementing new technology, especially in green field sites free of legacy infrastructures. Germany ( 21 percent), the United Kingdom (36 percent) and the United States (32 percent) have similar maturity footprints both in terms of 2015 
status and 2020 ambition. This could be because of their historical leadership in manufacturing. In France (14 percent), the Industrie 4.0 implementation was comparatively less mature. The economic downturn phase in 2015 and unsuccessful digitization programs could have been contributing factors.

\section{Objective and Goal: Development of the Acatech Industrie 4.0 Maturity Index}

The global benchmark on Industrie 4.0 maturity presented earlier clearly indicated an urgent need to act. Before this background, we present the approach and model developed by an industry consortium with the support of acatech in Germany. The model's approach is based on a succession of maturity levels, i.e. value-based development stages (see section 2.2.1) that help companies navigate their way through every stage in the digital transformation. To ensure that all aspects of manufacturing companies are taken into account, the model's structure is based on the "Production and Management Framework" by [6]. The framework's four structural areas enable a comprehensive analysis and set out a number of guiding principles that allow companies to identify which Industrie 4.0 capabilities they still need to develop. In the following, the underlying concepts and model of the acatech Industrie 4.0 Maturity Index are illustrated.

\subsubsection{Value-based Development Stages - Industrie 4.0 Maturity Levels}

As a first step, a general awareness is necessary that Industrie 4.0 can be achieved stepwise and according to individual company benefits. The basic structuring of Industrie 4.0 into successive stages is presented below in Fig. 3.1.

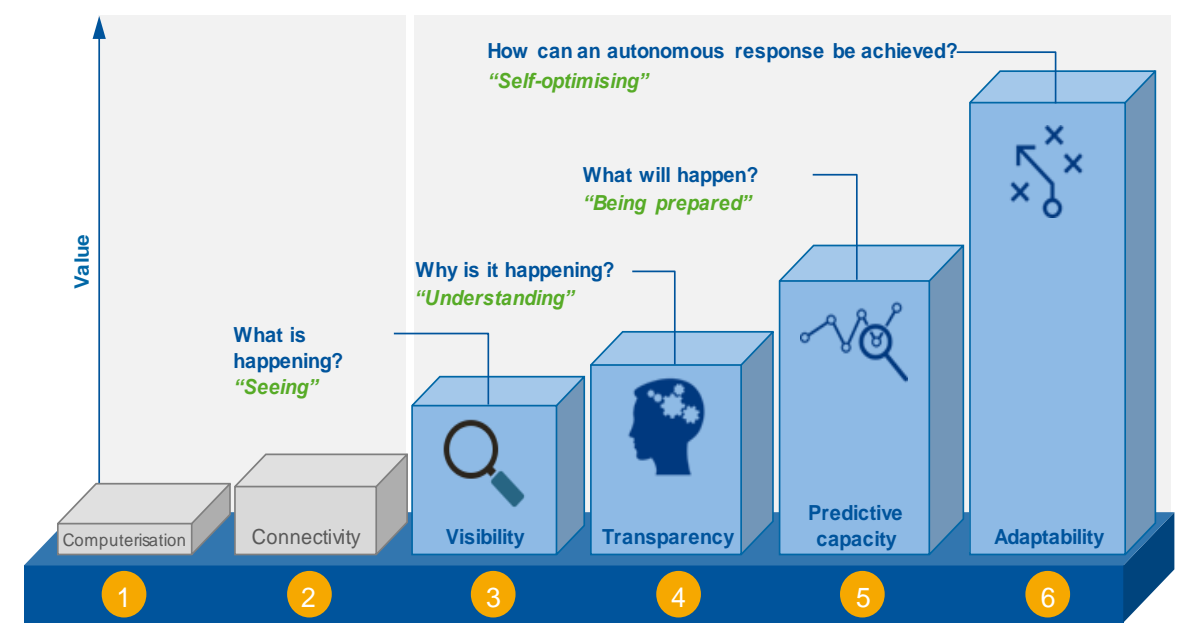

Fig. 3.1 Value-based development stages of Industrie 4.0 - Industrie 4.0 Maturity Levels [3]

The development path is based on computerization (1), which is the starting point for digitization and refers to the targeted use of information technologies. It enables 
cost-effective production with low error rates and generates the necessary precision, which is indispensable for the production of many modern products $[3 ; 9]$.

Achieving the connectivity level (2), the targeted or isolated use of IT is replaced by networked components. A complete integration between IT (information technologies) and OT (operative technologies) levels has not yet taken place; however, interfaces to business IT are provided by parts of implemented OT [3;11; 12].

Based on this, a digital visibility (3) is established with the help of sensors, which enable recording of processes from start to finish with a high amount of captured data. Processes states are no longer limited to individual areas, such as in a production cell, but can be extended to a production system or the entire company in real time in order to create a digital model, also known as the "digital shadow" [3; 7;9].

For a better causal understanding of processes, it is necessary to create further transparency (4) about the correlations in data stocks. Process knowledge is more and more required to support more complex decisions, which are based on semantic connections and aggregation of data.

Building up, the predictive capability level (5) enables simulation of different future scenarios and identification of those that are most likely. To this end, the digital shadow is projected into future-based scenarios and evaluated according to probability of occurrence. The ability to adapt (6) can enable an automatic reaction to expected machine failures or delays in delivery through a modified sequence in production planning.

\subsubsection{Required Capabilities for a Company's Structural Areas}

The skills that are relevant for the transformation of a manufacturing company into a learning, agile organization are assessed through the four structural areas of resources, information systems, culture and organizational structure (see Fig. 2.2). All of them characterize the structure of an organization and are examined over the six levels of the Industrie 4.0 development path, which is represented by six concentric circles in Fig. 3.2.

Each structural area is divided by two principles, each of which - depending on the benefit-oriented development levels - successively builds up skills. These skills guide the further development of the manufacturing company. The degree to which the abilities are implemented determines the maturity level of each principle. The maturity levels of the two principles are summarized and together they represent the evaluation of the structural area, which is oriented on the development levels.

The structural area resources includes all physical, tangible resources. This contains, for example, employees of a company, machinery and systems, the tools and materials used and the final product.

The two principles dividing this structural area are differentiated into digital competence and structured communication. "Digital competence" (a) characterizes the generation of data and its target-oriented independent processing into information by resources with corresponding technical components. This facilitates an informationdriven way of working, based on feedback from the process environments and not on forecast-based planning specifications. The skills of digital competence also include the use of embedded systems and the retention of digital competence, which can only 
be successful, if attention is paid to promoting interdisciplinary thinking and action by employees - if they are increasingly integrated into the innovation process. Through "structured communication" (b) collected information is linked and creates an overall picture. An efficient communication can be defined and interface designed in order to support decision-makers. [3; 7;8]

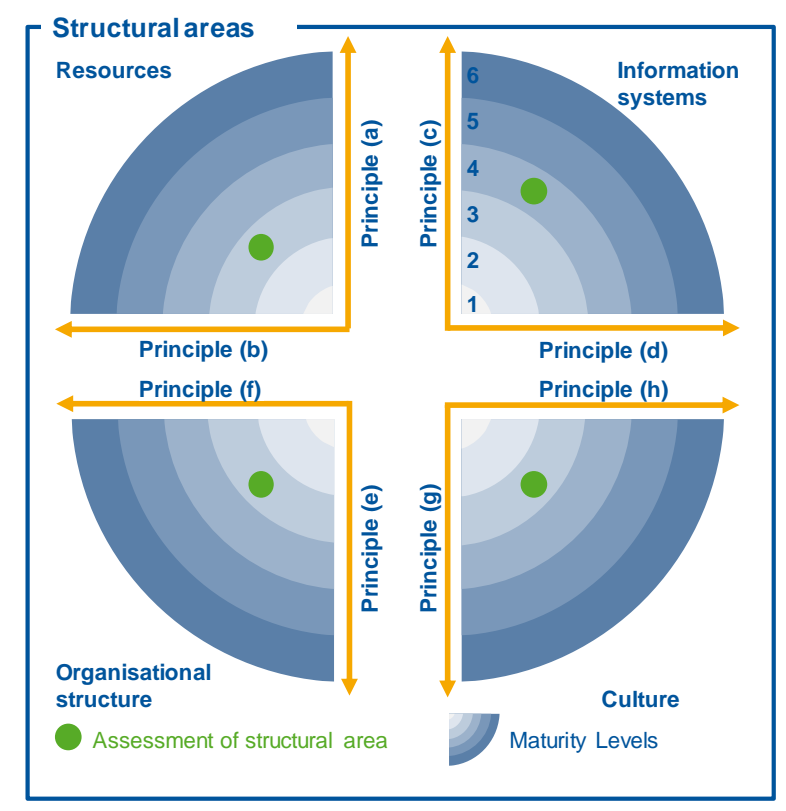

Fig. 3.2 Structure of the structural areas [3]

With the help of employees, information technologies and data information is available within information systems in accordance to economic criteria. Many manufacturing companies do not make sufficient use of data. The decisive factor is the insufficient processing of the collected data into information and its subsequent provision to the employees, which is why the first principle includes the processing and preparation of data (c) for decision support. This requires, among other things, context-based information provision, data storage and application-oriented interfaces in order to provide a technical infrastructure for real-time use of data and information ultimately [10]. In the context of the second principle, it is a question of integration for optimized data (d) use and increased agility under the primary aspect of data sharing within the value chain. However, this is only possible through the use of one leading information system that eliminates the need to keep duplicates in different IT systems. Standardized interfaces, detailed IT security and vertical and horizontal integration of information systems are required.

The transformation to a learning, agile company is achieved through the technologies explained above and the implementation of an appropriate organizational structure. In this model, the organizational structure refers on the one hand to the internal 
corporate organization (e) in the form of organizational structures and processes, and on the other hand describes the positioning in the value network (f). In contrast to the structural area culture described below, the organizational structure establishes mandatory rules that organize collaboration both within the company and externally. A high degree of individual responsibility on the part of employees is characteristic of the organic internal organization. In particular, dynamic collaboration requires skills that contribute to a smooth and automated exchange of information between companies [3].

A company's agility is highly dependent on the behaviour of its employees. In this context, two directions for changing corporate culture can be mentioned: willingness to change $(g)$ and social collaboration $(h)$. Willingness to adapt goes along with the prerequisite of being able to recognize opportunities for change and then initiate appropriate measures. In addition, it is advantageous to see mistakes not as a problem, but as an opportunity for positive change as well as a willingness to undergo continuous further training. The term social collaboration refers to the consideration of knowledge as a decisive guideline for action, which implies that an ideal state is characterized by making decisions based on knowledge [8].

The benefit levels presented allow companies to better assess their own Industrie 4.0 development and determine the next stage on their transformation path [2, 3].

\section{Application of the acatech Industrie 4.0 Maturity Index}

The application of the acatech Industrie 4.0 Maturity Index consists of three successive phases (see Fig. 4.1) [3] illustrated in the following.

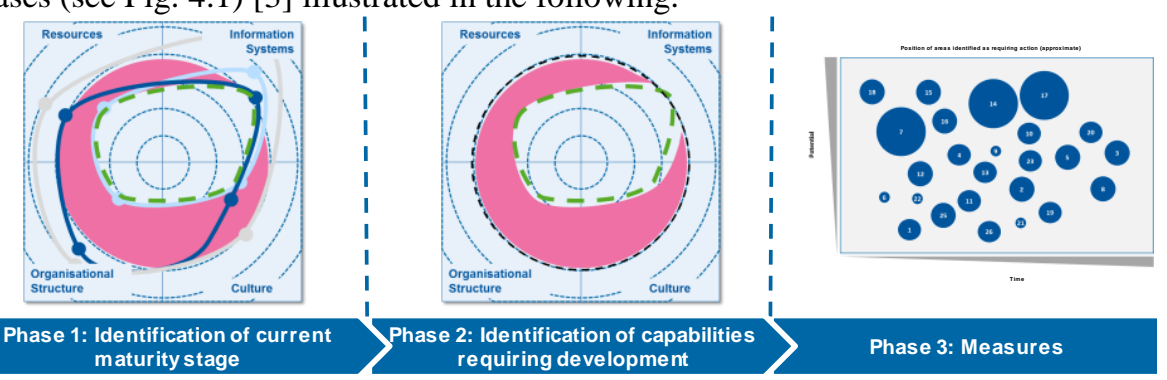

Fig. 4. 1 Application of the acatech Industrie 4.0 Maturity Index [3]

\subsection{Phase 1: Identifying the Current Industrie 4.0 Development Stage}

The company's location results from the six value-based development stages for Industrie 4.0 (see Section 2.1.1.) and the skills dedicated to them. For an appropriate assessment, the consortium has developed a questionnaire, with approx. 600 questions for the business processes engineering, production, logistics, service, sales and marketing. An inspection of a production plant can give a first impression of the processes, followed by a detailed evaluation of the business processes. The as-is analysis and the questionnaire is conducted based on the order processing process, which forms the framework 
situation for the evaluation of existing skills. With the help of a questionnaire evaluation the Industrie 4.0 Maturity Index and Levels can be identified for each structural area.

\subsection{Phase 2: Capabilities to be Acquired}

For the evaluation, the answers to the questionnaire shape the basis for the evaluation of the current situation of the company by the radar image (see Fig. 4.1). The dependencies of the structural areas determine consistent development in all structural areas as an essential goal. This is the basis for the recommendation for companies to approach the resulting areas of action and to strive for a consistent maturity stage across all four structural areas and in this way to use the maturity stage (achieve maturity stage consistency).

\subsection{Phase 3: Identifying Concrete Measures}

The next step is to derive measures addressing areas identified as requiring action. Necessary measures can be deduced from the missing capabilities evaluating the four structural areas. By evaluating individual processes, many individual measures can be dedicated, which makes it easier for companies to create a digital roadmap.

In defining strategic objectives for a company, identified measures are worked out precisely. Achieving the targeted stages of development, in turn, aims to support the realization of the strategic objectives formulated at the outset. This enables decisionmakers in manufacturing companies not only to identify at a glance the measures needed to achieve a higher maturity level, but also the interdependencies between identified measures. The purpose of this presentation is also to simplify the creation of a digitization roadmap by determining the order in which measures are implemented in terms of time and costs [3].

\section{$5 \quad$ Conclusion and Outlook}

The acatech Industrie 4.0 Maturity Index provides companies a supporting tool for transformation into a learning, agile company. This approach has proven in many cases to be of particular relevance for producing companies which has an outstanding role for more traditional structured, manufacturing based economies such as the European economy. It is important to differentiate this against more disruptive perspectives we know from venture capital driven and greenfield innovation in the IT-industry with its focus on end consumer offerings. The methodology describes six benefit-oriented development stages for four key areas. Each stage corresponds with additional, achievable benefits. This approach can be applied to develop a digital roadmap tailored to the needs of individual company in order to help them master the digital transformation if - as mostly in the case of the existing manufacturing and production industry - an evolutionary and structured transformation approach is the best choice. In this cases, the approach presented supports companies to guide their transformation in a very structured and most efficient and fast process. 


\section{References}

1. Schuh, G.; Jordan, F.; Maasem, C.; Zeller, V.: Industrie 4.0: Implikationen für produzierende Unternehmen. In: Digitale Transformation im Unternehmen gestalten. Geschäftsmodelle, Erfolgsfaktoren, Handlungsanweisungen, Fallstudien. Hrsg.: O. Gassmann; P. Sutter. Hanser, München 2016, p. 39-58

2. Schmitz, S.; Wenger, L.: Acatech Industrie 4.0 Maturity Index: Welche Fähigkeiten sind im Wandel entscheidend? In: IT\&Production (2017b) 5, S. 54 - 55.

3. Schuh, G., Anderl, R., Gausemeier J., ten Hompel, M., Wahlster, W. (Eds.): Industrie 4.0 Maturity Index. Managing the Digital Transformation of Companies (acatech STUDY), Munich: Herbert Utz Verlag 2017, p. 21

4. Infosys (2015): Industry 4.0. The state of the nations. 1. Aufl. Hg. v. Infosys Ltd. Bangalore, Indien.

5. Gudergan, G., Stich, V., Schmitz, S., Buschmeyer, A. (2016): The Global Evolution of The Industrial Internet of Things - A Cross Country Comparison Based on an International Study on Industrie 4.0 for Asset Efficiency Management. In: Proceedings of the International Conference on Competitive Manufacturing. Coma '16. February 2016, Stellenbosch, South Africa.

6. Boos, W./Völker, M./Schuh, G.: „Grundlagen des Managements produzierender Unternehmen“. In: Schuh, G./Kampker, A. (Hrsg.): Strategie und Management produzierender Unternehmen. Handbuch Produktion und Management 1, Berlin, Heidelberg: Springer Verlag (VDI-Buch) 2011, S. 1-62.

7. Bauernhansl, Thomas; Krüger, Jörg; Reinhart, Gunther; Schuh, Günther: WGP-Standpunkt Industrie 4.0. Hg. v. Wissenschaftliche Gesellschaft für Produktionstechnik Wgp e. V.

8. Zühlke, Detlef (2013): Die Cloud ist Voraussetzung für Industrie 4.0. Präsentation. VDI. VDI-Pressegespräch anlässlich des Kongresses „AUTOMATION 2013“. Baden-Baden, $6 / 25 / 2013$

9. Schuh, G.; Potente, T.; Thomas, C.; Hauptvogel, A. (2014): Steigerung der Kollaborationsproduktivität durch cyber-physische Systeme. In: Thomas Bauernhansl, Michael ten Hompel und Birgit Vogel-Heuser (Hg.): Industrie 4.0 in Produktion, Automatisierung und Logistik. Wiesbaden: Springer Fachmedien Wiesbaden, S. 277-296.

10. Hering, Niklas; Brandenburg, Ulrich; Frey, Dominik; Ihne, Manfred; Meißner, Jan; Reschke, Jan; Schenk, Michael (2015): Smart Operations. Hg. v. FIR an der RWTH Aachen. Aachen.

11. Vogel-Heuser, Birgit (2014): Herausforderungen und Anforderungen aus Sicht der IT und der Automatisierungstechnik. In: Thomas Bauernhansl, Michael ten Hompel und Birgit Vogel-Heuser (Hg.): Industrie 4.0 in Produktion, Automatisierung und Logistik. Wiesbaden: Springer Fachmedien Wiesbaden, S. 37-48.

12. Kaufmann, Thomas; Forstner, Lisa (2014): Die horinzontale Integration der Wertschöpfungskette in der Halbleiterindustrie. Chancen und Herausforderungen. In: Thomas Bauernhansl, Michael ten Hompel und Birgit Vogel-Heuser (Hg.): Industrie 4.0 in Produktion, Automatisierung und Logistik. Wiesbaden: Springer Fachmedien Wiesbaden, S. 359-367. 